\title{
GENERATING ELECTRICITY BY FOOTPATH POWER GENERATOR FLOOR TILES
}

\author{
${ }^{1}$ Dr.R.Mohanapriya, ${ }^{2}$ R.S.Hemalatha, ${ }^{3}$ K.Jayashree, ${ }^{4}$ D.Nithya \\ ${ }^{1}$ Associate professor, Department of Electronics and communication Engineering, Paavai Engineering \\ College, Namakkal, Tamilnadu ,India \\ ${ }^{234}$ UG Students, Department of Electronics and communication Engineering, Paavai Engineering \\ College, Namakkal, Tamilnadu ,India
}

\begin{abstract}
Walking is the most common movement in human life. When a person walks, he distributes energy to the road surface in the form of impact, vibrations, sound etc, due to the transfer his weight on the road exterior, through foot falls on the ground during a every steps. This energy Can be tapped and transformed in the practical form such as in electrical form. In order to develop a procedure to connect footstep energy, we are developing a footstep electricity generating device. This device, if embedded in the footpath can varying foot impact energy into electrical energy. The working principle, when a pedestrian step on the upper plate of the device, the plate will dip down to some extent due to the weight of the pedestrian. The descendant movement of the plate results in sturdiness of the piezoelectric materials fitted in the device to produce electrical energy the device was worked by persons walking over to it. However, if there is determined movement of pedestrians over the device, a large amount power will be a formed in this research a prototype of the power producing tiles is developed and studied under varying loading environments to inspect the feasibility of the technology.
\end{abstract}

\section{INTRODUCTION}

Energy is nothing but the capability to do the work. In today life, Electricity is most commonly used energy resource. Now-a-days energy claim is increasing and which is lifeline for persons. Due to this amount of energy resources are generated and wasted. Electricity can be generated from properties like water, wind etc. to produce the electricity from these sources development of large plants is needed having high maintenance cost. Some other 
stepping on star. The use of stairways in every building is increasing day by dayeven trivial building has some floors when we are stepping amount of this wasted energy is utilized and converted to electricity by Piezoelectric effect to generate an electric charge in response to applied mechanicalstress

\section{LITERATURE REVIEW ANALYSES}

According to this paper deals with design and modeling of parts of the model of the foot step power generation system using assemblage of gearbox with sprocket When a person jumps, he drops energy to the ground surface in the form of impact, vibration, sound etc., due to the transfer of his weight on to the ground surface, through feet falls on the ground during every leap. This energy can be tapped and transformed into usable electric form. This motion is then transported to the output gear through the in-between gears and the sprocket. Thus, both the motion of the rack is utilized that is upward and downward. The motion at the output gear causes the dynamo to generate electricity [1].

This Paper states that the most suitable method for obtaining the energy surrounding a system is achieved by using piezoelectric crystals. Piezoelectric quartzes are one of small-scale energy sources. The piezoelectric crystals are exposed to vibration they generate a very slight voltage, commonly known as piezoelectricity. It has a crystalline formation that translates an applied vibration into an electrical energy the piezoelectric effect exists in two properties the first is the direct piezoelectric effect that defines the materials ability to convert mechanical strain into electrical charge. The second form is the opposing effect, which is the capability to convert an applied electrical potential into mechanical strain energy. These properties allow the material to function as a power harvesting medium [2].

This statement of Albert Einstein is true "Energy can neither be formed nor be ruined it can be transferred from one form to another." This method of generating electricity by the usage of piezoelectric material has already existence in progress in numerous countries viz Japan, Israel, Netherlands. Usage of piezoelectric material is eco- friendly causes no contamination. It is an reasonable way of generating electricity and is easy to mount. In future this technique will be a promising method for producing eco- friendly electricity. We also contribute this process at public places like home entrance gates, parking area, bus stands etc. This method will exploit different areas of electricity generation [3].

The piezoelectric crystals yield the voltage which can be use for power various things. The piezoelectric crystals have a crystal-like structure which converts an applied vibration into an electrical energy. Piezoelectricity states to the ability of some materials to generate an electric potential in response to applied 
compression Embedded piezo-electric crystals provide the ability to convert the human walking energy into the electric current due to the applied pressure.This paper comprises of four section namely study of piezoelectric material, application of energy harvesting via piezoelectric material, locations for generating large scale electricity [4].

\section{WORKING PRINCIPLE}

The aim of the proposal is to Energy harvesting from the roads by piezoelectric sensors/crystals using Internet of Things, this helps to save energy by using the stored energy instead of the normal power supply. The piezoelectric sensor array is placed on the roads in various places as shown in the system design, the whole array is connected as one compartment which generates the electrical energy from the mechanical energy, and the generated electrical energy is send to the rectifier which converts the current from alternate to direct current. The produced current is stored in the battery for further usage; the micro controller controls the system and the street light, signals etc. All the process is displayed with the help of display unit

This paper is concerned with generation of power from ,,power step ${ }^{\text {ee }}$ set up. The human weight turns upon the Power step-setup will produce direct reciprocating motion on the power step. Here the reciprocating motion of the power step is transformed into rotating motion using the crankshaft arrangement. A flywheel is used to produce rotary motion. The flywheel and the power step pedal are associated by means of connecting rod The rotary motion of huge flywheel is given to the small pulley by belt or chain. Hence the speed that is accessible at the flywheel is relatively reproduced by the rotation of the smaller pulley. this speed is adequate to rotate the rotor of $\mathrm{a} 12 \mathrm{~V}$ generator. The rotor which rotates within a static magnetic stator slashes the magnetic flux surrounding it, thus fabricating the electro motive force (emf). This formed emf is then sent to an inverter, where the produced emf is regulated. This regulated emf is now directed to the storage battery where it is deposited. This current is then used for further purposes. The generator converts the mechanical rotating motion into electrical energy.

Piezoelectric crystals are the energy sources. The piezoelectric crystals yield the voltage which can be use for power several things. The piezoelectric crystals have a crystal-like structure which alters an applied vibration into an electrical energy. 


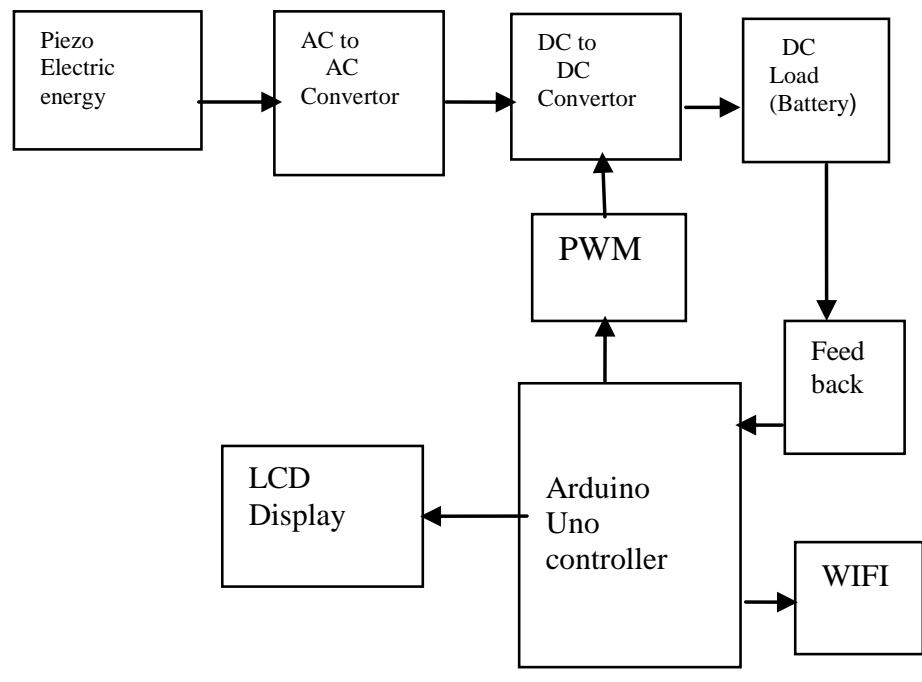

Piezoelectric is found in a ration of everyday

Piezoelectricity denotes to the ability of virtually materials to generate an electric potential in response to applied pressure Embedded piezo-electric crystals deliver the ability to convert the human walking energy into the electric current due to the applied pressure. This paper embraces of four segments namely study of piezoelectric material, application of energy harvesting via piezoelectric material, locations for generating large scale electricity.

\subsection{COMPONENTS}

\section{Piezoelectric energy}

The Piezoelectric effect changes kinetic energy in the form of vibrations or shockwaves into electrical energy. Piezoelectric Material proposal a strong and dependable resolution by renovating mostly wasted vibration energy in the atmosphere to operational electrical energy. electronic device, from quartz watches to speakers and microphone. Piezoelectricity is the procedure of using crystals to alter mechanical energy into electrical energy or vice versa.

\section{Boost converter}

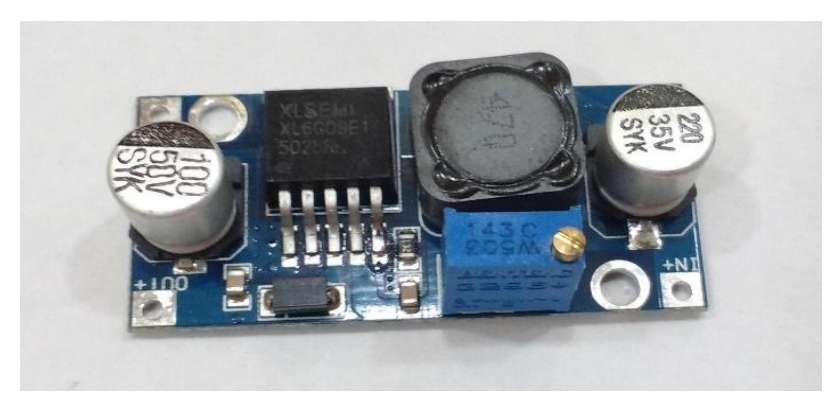

It operates from a wide-ranging input range of $36 \mathrm{Vdc}$ to $75 \mathrm{Vdc}$ and affords a controlled output voltage of $28 \mathrm{Vdc}$ the output is rated to a power level up to (450Watts). It also has an aid pin on the primary side of the converter

\section{Load (Battery)}

DC load are instruments which collecta direct current (DC) from a source. Generally used for Test and measurement purposes, DC electrical loads can be automated to determine the current, the Voltage and frequency existing in 
circuits and electrical systems.

\section{Pulse Width Modulation}

Pulse Width Modulation or PWM is a procedure for getting analog results with digital means digital switch is used to create a square wave, a signal switched mid on and off. It is used for controlling the amplitude of digital signals in command to control devices and applications demanding power or electricity

\section{Arduino Uno Controller}

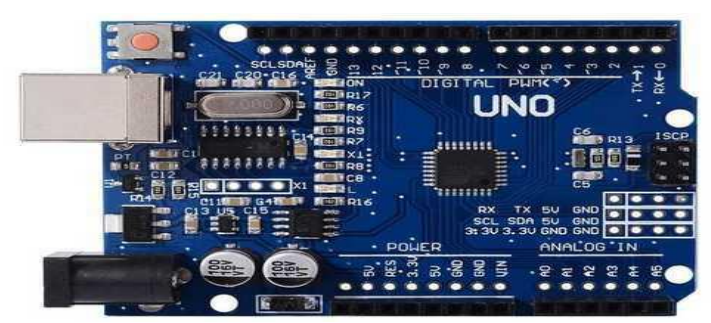

Arduino Uno is a microcontroller panel built on the ATmega328P. It has 14-digit input/Output pins, 6 analog inputs, a $16 \mathrm{MHz}$ stoneware resonant circuit (CSTCE16MOV53-RO), a USB assembly a control jack, an ICSP header and a reset button

\section{LCD DISPLAY:}

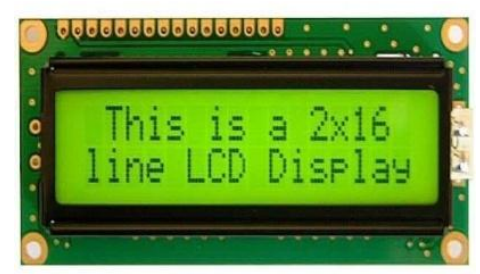

A liquid crystal display (LCD) is a flat electric realistic display that customs the light controlling effects of liquid crystals (LCs). LCs do not produce light directly.

\section{INTERNET of THINGS (IoT):}

The Internet of things (IoT) is the grid of physical devices, vehicles, household appliances, and other things fixed with electronics, software program, sensors, actuators, and connectivity which enables these things to connect, collect and exchange data.

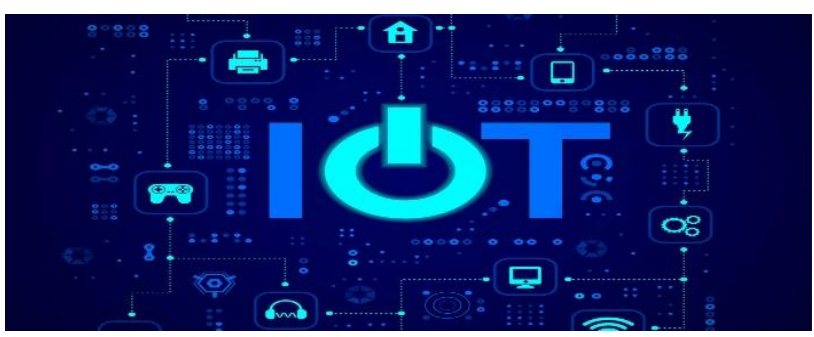

IoT involves delivery Internet connectivity out their ordinary devices, such as desktops, laptops, smartphones and tablets, to any range of usually non-internet-enabled physical devices and everyday objects

\section{WIFI (IoT)}

WIFI is exclusively placed to support broadband and narrowband IoT applications from a common Dais that can work at varying

\begin{tabular}{|l|l|}
\hline Current Rating & $7.91 \mathrm{~A}$ \\
\hline Battery voltage & $12.20 \mathrm{~V}$ \\
\hline Current Delivered & $7.91 \mathrm{~A}$ \\
\hline PV power output & $95 \mathrm{~W}$ \\
\hline Solar panel & $140 \mathrm{~W}$ \\
\hline $\begin{array}{l}\text { Maximum Battery } \\
\text { voltage }\end{array}$ & $32 \mathrm{~V}$ \\
\hline
\end{tabular}

levels of power consumption and signal range. 


\begin{tabular}{|l|l|l|}
\hline Feature & $\begin{array}{l}\text { WIFI } \\
(802.11 \mathrm{~b})\end{array}$ & $\begin{array}{l}\text { WIFI } \\
(802.11 \mathrm{a} / \mathrm{g})\end{array}$ \\
\hline $\begin{array}{l}\text { Frequency } \\
\text { band }\end{array}$ & $\begin{array}{l}2.4 \mathrm{GHz} \\
\text { ISM }\end{array}$ & $\begin{array}{l}2.4 \mathrm{GHz} \quad(\mathrm{g}) \\
5 \mathrm{GHz}\end{array}$ \\
\hline $\begin{array}{l}\text { Channel } \\
\text { band width }\end{array}$ & $25 \mathrm{MHz}$ & $20 \mathrm{MHz}$ \\
\hline $\begin{array}{l}\text { Half /Full } \\
\text { duplex }\end{array}$ & Half & Half \\
\hline $\begin{array}{l}\text { Radio } \\
\text { technology }\end{array}$ & $\begin{array}{l}\text { Direct } \\
\text { sequence } \\
\text { spread } \\
\text { spectrum }\end{array}$ & $\begin{array}{l}\text { OFDM (64 } \\
\text { Channels })\end{array}$ \\
\hline
\end{tabular}

\section{CONCLUSION}

Footstep power generation structure is economical, reasonable energy solution to common persons. It can be used for many applications in rural areas where power availability is less or totally absence. the power using footstep get its energy requirements from the non- renewable source of energy. It is very useful to the places all roads and as well as all kind of footstep which is used to generate the nonconventional energy like electricity. It is one of the smart systems here is no need of power from the mains and there is less pollution in this source of energy. This project is aimed to preserve our environment from various effects of different methods of power generation It is able to extend this project by using same arrangement and construct in the footsteps/speed breaker so that rise the power construction rate by fixing school and highways etc.

\section{REFERENCES}

[1] Prabakarn R, Jayapakash A, Vijay Anand. "Power Harvesting by Using Human Foot Step"- International Journal of Innovative Research in Science Engineering and Technology, vol.2, issue 7, July 2013.

[2] Ramesh Raja R, Sherin Mathew" Power Generation from Staircase (steps)"International Journal of Innovative Research in Science Engineering and Technology, vol.3, Issue 1, February 2014.

[3]Patel Kamalesh, Pandya krunal, Patel Ronak, Prajapati Jayadeep ,Sorathiya Mehul "Design of Foot step power Generation systems", 2 nd International Conference on Current Research Trends in Engineering and Technology ,2018, IJSRSET ,Volume 4, Issue 5 .

[4]ITIKA Tandon, Alok Kumar" A Unique Step towards Generation of Electricity via New Methodology"- International Journal of Advanced Research in Computer and Communication Engineering, vol.3, Issue 10, October 2014.

[5]Kiran Boby, Aleena Paul K, Anumol C.V, Josine Ann Thomas, Nimisha K.K Footstep Power Generation Using Piezoelectric Transducer"- International Journal of Engineering and Innovative Technology, vol.3,Issue 10,April 2014.

[ 6] Jose Ananth Vino, AP." Power Generation Using Footstep"- International Journal of 
Engineering Trends and Technology, vol.1, Issue 2, May 2011.

[7]Chandra Sekhar, B Maruti Kishore, T Jogi Raju” Electromagnetic Foot Step Power Generation"- International Journal of Scientific and Research Publication, vol.4, Issue 6, June2014.

[8]ShiraJ Afzal, Farrukh Hafeez" Power Generation Footstep"- International Journal of Advancement in Research and Technology, vol.3, Issue 4, April 2014.

[9]K. Ramakrishna, Guruswamy Ravana, Venu Madhav Gopaka" Generation of electrical Power through Footsteps"- International Journal of Multidisciplinary and Current Research September 2014.

[10] Umeda, M., Nakamura, K., and Ueha, S. Energy Storage Characteristics of a Piezo generator Using Impact Vibration,Japan Journal of Applied,1997, Vol 36. 